\title{
O ENSINO DE LÍNGUA PORTUGUESA E O INGRESSO DE ALUNOS INDÍGENAS NO ENSINO SUPERIOR
}

\author{
NASLE MARIA CABANA ${ }^{1}$ \\ FACISABH, BRASIL \\ https://orcid.org/0000-0003-4732-1402 \\ CLEIDE PEREIRA FERNANDES ${ }^{2}$ \\ FACISABH, BRASIL \\ https://orcid.org/0000-0003-0084-5516
}

\begin{abstract}
RESUMO: Neste artigo, foi apresentada uma breve discussão sobre a pouca inclusão do aluno indígena no ensino superior. Este fato foi relacionado ao baixo desempenho em língua portuguesa na modalidade exigida nos exames de seleção. A pesquisa foi motivada ao se constatar que, embora a legislação brasileira assegure a educação básica de qualidade para todos os brasileiros, há um número reduzido de estudantes indígenas que atingem o ensino superior. O resultado foi obtido a partir da avaliação de desempenho em língua portuguesa aplicada a um grupo de jovens estudantes e concluintes do ensino médio e da Eja e foi constatado que o ensino é insatisfatório na comunidade pesquisada. Contudo, a pesquisa também mostrou que esse resultado pode ser equiparado à média de desempenho das escolas da rede pública.
\end{abstract}

PALAVRAS-CHAVE: Educação escolar indígena, desempenho em língua portuguesa, letramento.

ABSTRACT: In this paper, it was showed a brief discussion about little inclusion of indigenous students in university education. This fact was related to the poor performance in portuguese in the modality required in the selection exams. The research was motivated by finding that, although brazilian legislation ensures quality basic education for all Brazilians, there are a small number of indigenous students who reach university education. The result was obtained from the portuguese language performance evaluation applied to a group of young students and high school graduates and Eja it was found that the teaching is unsatisfactory in the researched community. However, research has also shown that this result can be compared to the average performance of public schools.

KEYWORDS: indigenous school education, portuguese language performance, literacy.

\footnotetext{
${ }^{1}$ Doutora em Linguística pela UFMG. Docente na Faculdade de Ciências Sociais Aplicadas de Belo Horizonte. E-mail: naslemc@hotmail.com

${ }^{2}$ Graduanda em Letras na Faculdade de Ciências Sociais Aplicadas de Belo Horizonte. E-mail: cleidepfernandes@hotmail.com
} 


\section{Introdução}

Nesse artigo, apresentamos o resultado de uma pesquisa cujo objetivo era investigar razões pelas quais há um número relativamente reduzido de indígenas cursando o ensino superior (ou que já tenham concluído) ${ }^{3}$. Ações afirmativas e políticas de inclusão têm contribuído para mudar esse quadro, pois, a partir dessas ações, houve, segundo o Instituto Nacional de Estudos e Pesquisas Educacionais Anísio Teixeira (Inep), um aumento de alunos ingressantes no ensino superior nos últimos anos. Entre 2015 e 2016, o número de alunos matriculados aumentou $52,5 \%$ e de concluintes $32,18 \%{ }^{4}$ Contudo, o número de inscritos no Enem de pessoas que se declararam indígenas em 2017 foi de $0,7 \%$, o que consideramos um baixo índice de procura.

É importante lembrar que a educação escolar indígena tem suas especificidades, e há uma preocupação das lideranças em fornecer ensino adequado a suas crianças e jovens. Diferente de outras épocas em que a educação escolar era fornecida pelo Estado como forma de integrar esses povos a sociedades não indígenas, observaram-se, nas últimas décadas, reivindicações dos próprios indígenas para uma educação intercultural, adequada e efetiva. Essas reivindicações vieram justamente atender às necessidades locais, inclusive de formação em nível superior para suprir a carência de professores para atuar nas aldeias, além de profissionais da saúde, entre outros. Por essa razão, há mobilizações para formação apropriada de seus professores, que estão sendo concretizadas por meio da oferta de licenciaturas interculturais em várias instituições de ensino superior públicas no país. Segundo a Funai $^{5}$, essas medidas vêm ocorrendo "a fim de fortalecer o projeto de autonomia dos povos e organizações indígenas". Sabemos, entretanto, que os desafios encontrados por esses povos ainda são muitos. Ao ingressarem no ensino superior, enfrentam dificuldades, dentre as quais constam a ausência das famílias - que ficam nas aldeias -, dificuldades financeiras e diferenças linguísticas e culturais.

Sendo assim, nossa pesquisa visou verificar se o grau de conhecimento em língua portuguesa, conforme exigido nos exames para o ingresso no ensino superior, seria um entrave para os alunos. Para isso, aplicamos uma avaliação contendo questões de interpretação de texto e dissertativas a fim de diagnosticar o desemprenho de um grupo de alunos indígenas do ensino médio e concluintes (incluindo da Eja) de uma comunidade da etnia Pataxó de Minas Gerais que vive no município de Carmésia. Reconhecemos que o número de participantes envolvidos

\footnotetext{
${ }^{3} \mathrm{O}$ trabalho completo resultou na monografia Letramento em língua portuguesa: um instrumento para o ingresso do indígena na universidade, de Cleide Pereira Fernandes, defendida em 11/12/2018 na Faculdade de Ciências Sociais Aplicadas de Belo Horizonte (FACISABH) sob a orientação da professora doutora Nasle Maria Cabana.

${ }^{4}$ Fonte: http://www.funai.gov.br/index.php/comunicacao/noticias/4720-cresce-o-numero-de-estudantesindigenas-nas-universidades Acesso: 26/09/2019

${ }^{5}$ http://www.funai.gov.br/index.php/educacao-escolar-indigena?start=6 Acesso 23/09/2020
} 
tenha sido pouco expressivo, não servindo de parâmetro para um quadro mais amplo. Porém, acreditamos que os resultados podem motivar novas investigações com um número maior de participantes e envolvendo outras comunidades com realidades linguísticas diferentes. Assim, caso seja verificado baixo desempenho, novas abordagens metodológicas devem ser procuradas para um ensino mais satisfatório a fim de atender as necessidades locais. Após nossa análise, observamos que o desempenho dos alunos da comunidade pesquisada, se comparado aos resultados do Sistema Nacional de Avaliação da Educação Básica (SAEB), confirma que há uma deficiência generalizada na educação do país, não sendo uma característica apenas da educação indígena ofertada na comunidade Pataxó mencionada. Esse resultado pode ter correlação com o fato de que, nessa comunidade, os falantes possuem a língua portuguesa como língua materna. O desafio é atingir o letramento, que consiste em usar a língua adequadamente em conformidade com as diversas situações comunicativas, o que inclui a modalidade escrita padrão, exigida em exames de seleção. Esse desafio é o mesmo para grande parte dos estudantes das redes públicas de ensino.

Antes de apresentarmos os resultados de nossa pesquisa, nas próximas seções, abordaremos brevemente o contexto da educação escolar indígena no Brasil e a educação em comunidade bilíngue. Com isso pretendemos apresentar um panorama dos desafios para oferta adequada do ensino de línguas em diferentes comunidades.

\section{O contexto da educação escolar indígena}

A educação escolar indígena é permeada por desafios, sobretudo quando a questão é decidir sobre ações mais adequadas a serem tomadas tendo em vista contextos culturais bem peculiares. Um dos grandes desafios está relacionado à escolha do modelo de ensino de língua em comunidades cuja população é, em grande parte, bilíngue. Amaral (2011), em seu artigo Bilinguismo, aquisição, letramento e o ensino de múltiplas línguas em escolas indígenas no Brasil, explica que há uma demanda do ensino da língua portuguesa, enquanto ferramenta para suprir várias necessidades cotidianas como a de se comunicar com população não indígena, além de servir de instrumento para sua defesa diante da sociedade nacional. Evidentemente, há também consenso sobre a importância do ensino da língua indígena como forma de manutenção e valorização cultural. Na prática, Maia et at (2002) ressaltam que o levantamento do MEC constatou pouca presença do uso de línguas nativas nos espaços escolares, embora houvesse a pretensão de que fossem bilíngues. Os autores elaboraram uma proposta de currículo para a área "Língua, Arte e Literatura" visando a formação de educadores indígenas da Universidade Estadual do Mato Grosso (UNEMAT) e uma das reivindicações dos alunos-professores indígenas era o estudo do português, pois sentiam necessidade de se comunicar de forma efetiva com a sociedade. 
Neste artigo, não iremos nos alongar em reflexões sobre a relevância de uma educação bilíngue, prática que é realidade em algumas comunidades. Nosso objetivo é apresentar o resultado de uma pesquisa que foi desenvolvida com o propósito de responder a seguinte questão "por que ainda há relativamente poucos indígenas cursando ensino superior?" Nossa hipótese era de que o processo de ensino/aprendizagem em língua portuguesa não estaria sendo adequado para que os alunos atingissem proficiência suficiente para participarem do Exame Nacional do Ensino Médio (ENEM) ou de vestibulares (como ainda é o processo seletivo em algumas instituições) com bons resultados. Em muitas comunidades indígenas no Brasil, as escolas ficam na própria aldeia e é comum seus professores não terem uma formação acadêmica adequada. Ou ainda, quando há professores não indígenas atuando nas escolas, há dificuldades de adaptação diante de realidades culturais diferentes. Além disso, na publicação "Estatísticas Sobre Educação Escolar Indígena no Brasil"6 (2007, p.21), levantamento realizado em 2005, há apontamentos que identificam uma deficiência no ensino devido à falta de regularização do ensino aos índios de modo geral. Comprovou-se sua pouca formalização, além da falta de materiais e de infraestrutura. Tudo isso justificaria um resultado não satisfatório.

Diante das dificuldades e necessidade de formação de profissionais com ensino superior, inclusive para atuarem na área da educação, foram criados alguns programas de incentivo à formação indígena. Um deles, publicado no Diário Oficial da União em 13 de maio de 2013, foi a criação do Programa de Bolsa Permanência ${ }^{7}$ (PBP). Um de seus objetivos é, segundo o art. $3^{\circ}$, "viabilizar a permanência, no curso de graduação, de estudantes em situação de vulnerabilidade socioeconômica, em especial os indígenas e quilombolas". Trata-se de um auxílio financeiro cuja finalidade é minimizar as desigualdades sociais, étnico-raciais e contribuir para permanência e diplomação dos estudantes de graduação. Além disso, os estudantes podem contar com $\operatorname{cotas}^{8}$ nas instituições federais e PROUNI.

Ressaltamos que a política educacional implementada pelo MEC para os povos indígenas é pautada pela oferta de uma educação escolar específica, diferenciada, intercultural, bilíngue e com a disponibilidade de cotas para atender esses alunos. Além disso, também tem como objetivo garantir a essas populações a recuperação de suas memórias históricas, a reafirmação de suas identidades étnicas e a valorização de suas línguas e ciências, bem como o acesso às informações e aos conhecimentos técnicos e científicos da sociedade nacional (AMARAL, 2011, p.14). Apesar da legislação e políticas educacionais, poucos alunos indígenas conseguem ingressar no ensino superior. Ainda não se vê um número

\footnotetext{
${ }^{6}$ Disponível em: www.portal.inep.gov.br

${ }^{7}$ (BRASIL, 2004) através da Lei $\mathrm{n}^{\circ} 11.096$ (BRASIL, 2005)

${ }^{8}$ Lei no 12.711 (BRASIL, 2012) criada e sancionada em 29 de agosto de 2012 que reserva no mínimo 50\% das vagas das instituições federais de ensino superior e técnico para estudantes de escolas públicas, que são preenchidas por candidatos autodeclarados pretos, pardos e indígenas, em proporção no mínimo igual à presença desses grupos na população total da unidade da federação onde fica a instituição.
} 
expressivo desses estudantes beneficiando-se desses programas e de seus direitos garantidos por lei.

\section{A educação em comunidade bilíngue}

Na tentativa de compreender esse quadro, fizemos um pequeno levantamento sobre estratégias que seriam recomendadas para um ensino intercultural mais adequado. Amaral (2011) faz uma abordagem sobre a educação em comunidades bilíngues e distingue o processo de aquisição de uma língua do processo de letramento, noções importantes para avaliar realidades linguísticas. A aquisição, segundo o autor, é um processo inconsciente em que os falantes se apropriam de conhecimentos sobre fonética, fonologia, morfologia, sintaxe, semântica e pragmática. $O$ letramento, por sua vez, é um processo que deverá ser guiado pelo professor para que o aluno, além de aprender a representação gráfica dos sons, aprenda padrões estilísticos selecionados socialmente. Os alunos devem perceber as diferenças dialetais e usar aquelas adequadas às distintas situações sociais. (AMARAL, 2011 , p.21). $O$ autor adverte para 0 fato de que, às vezes, durante o processo de ensino-aprendizagem, o professor não faz um diagnóstico adequado de um desvio como sendo um problema na aquisição da língua - que ainda não se efetivou adequadamente - ou um erro decorrente da pouca habilidade no uso da escrita, por exemplo. Por isso reivindica um levantamento do conhecimento linguístico dos alunos, para que sejam adotadas estratégias pedagógicas diferenciadas. Em termos práticos, o ideal é que o professor exponha os alunos a situações comunicativas para garantir a possibilidade de seu uso efetivo. Esta é, na verdade, a orientação que vem norteando todo ensino de língua portuguesa na educação básica no Brasil nas últimas décadas, segundo uma visão interacionista da língua. Nessa perspectiva, as práticas de ensino devem resultar em usos proficientes considerando as diferentes situações comunicativas às quais estamos expostos. Antunes (2003, p.41), assumindo esta visão, afirma que as línguas só existem para promover a interação entre as pessoas, admitindo que somente esta concepção, funcional e contextualizada, pode fundamentar o ensino de língua. Além disso, o currículo escolar deve proporcionar oportunidades para que o aluno possa desenvolver seus conhecimentos sobre diversos conteúdos ao mesmo tempo em que pratica suas habilidades linguísticas. (AMARAL, 2011, p.19)

Campetela (2014), por sua vez, enfatiza a necessidade de uso de material didático contextualizado para os alunos indígenas. Não seria eficaz, segundo a autora, um material que não contemplasse um perfil etnográfico que não valorize a cultura brasileira regional, tanto quanto a indígena. Dessa forma abre-se espaço para reflexões sobre a estrutura escolar, políticas públicas e ensino, diversidade cultural e legitimação da norma-padrão. Nesse sentido, a autora adverte que os materiais didáticos de Língua Portuguesa propostos para escolas indígenas são elaborados com um crescente aproveitamento endógeno, isto é, do conhecimento que o próprio povo possui. Esta medida, segundo Campetela, torna-o 
insuficiente porque não permite o conhecimento pleno da língua, o que impede a troca de conhecimentos. Ela ressalta ainda que há relatos de professores indígenas que denunciam pouca habilidade para trabalhar com o português por não possuírem contato suficiente com falantes e pelo fato de os materiais didáticos não trazerem informações consistentes para que se aprenda sobre a utilização da língua e sobre a cultura daqueles que a utilizam. Deve ficar claro que não se trata de desapropriação da cultura indígena, mas de instrumentalizar os indígenas para o aprendizado da língua portuguesa como segunda língua, se for o caso $^{9}$. E sabe-se que "a escrita supõe condições de produção e recepção diferentes daquelas atribuídas à fala" (ANTUNES, 2003, p.50). Portanto, apenas a proficiência na oralidade não fornece condições suficientes para promover engajamento no nível superior, o que é objeto de nosso trabalho.

É oportuno lembrar que os problemas educacionais não se restringem a essas comunidades, mas também aos não indígenas. Há um déficit com relação aos resultados esperados em todo território nacional e que já vem sendo denunciado por profissionais da área. Antunes (2003) fala do insucesso do aluno, que se manifesta nas dificuldades de leitura e escrita. Magda Soares (2004) revela que, nos últimos trinta anos, foram identificados vários problemas na alfabetização que levaram a resultados insatisfatórios. Esses resultados foram apontados por estatísticas de avaliações estaduais e nacionais e vêm provocando críticas, mas também produzindo propostas para uma nova abordagem de ensino e para mudanças nas práticas existentes. Esperamos que, com nossa pesquisa, possamos contribuir para a elucidação desse quadro.

\section{Os envolvidos na pesquisa}

Para avaliarmos nossa hipótese, de que o ensino da língua portuguesa em comunidades indígenas não estaria capacitando adequadamente os alunos do ensino médio para a realização de exames - o que estaria sendo um obstáculo para o ingresso no ensino superior , selecionamos uma comunidade indígena para nossa investigação. 0 objetivo foi verificar o grau de conhecimento da modalidade escrita padrão da língua portuguesa. Não tínhamos, obviamente, a pretensão de que os resultados refletissem o comportamento linguístico de todas as comunidades indígenas do Brasil que, como se sabe, apresentam realidades muito diferentes. Esperávamos, entretanto, que pudessem indicar o grau de suficiência da modalidade padrão da língua e sinalizar se seria ou não um impedimento para o ingresso no ensino superior. A etnia escolhida para o nosso trabalho foi a Pataxó ${ }^{10}$, da comunidade

\footnotetext{
${ }^{9}$ Em algumas comunidades, a língua portuguesa é a segunda língua e, em outras, a primeira.

${ }^{10}$ Segundo informações do site Povos Indígenas do Brasil - PIB (2012), essa população vive em diversas aldeias no extremo sul do estado da Bahia e norte de Minas Gerais. Há evidências de que uma das aldeias, a de Barra Velha, existe há quase dois séculos e meio, desde 1767. Por terem vivido vários conflitos com os não índios desde o século XVI e muitas vezes obrigados a esconder seus costumes, hoje se esforçam para retomar sua língua denominada Patxohã e seus antigos rituais como o Awê. Por essa razão, sua
} 
localizada no município de Carmésia, Minas Gerais. É importante destacar que a língua portuguesa é a primeira língua deles e há um processo de retomada da língua indígena, chamada Patxohã.

Incialmente procuramos, junto às autoridades locais, informações sobre a escola da comunidade, seus professores e o interesse dos alunos em cursar o ensino superior. Fomos informados de que a escola é da rede estadual de Minas Gerais - Escola Estadual Bacumuxa Pataxó - e que fica localizada dentro da aldeia. Seus professores são da própria comunidade e foram alunos também da escola. A maioria tinha apenas o ensino médio. Um havia iniciado um curso de magistério de ensino médio e uma professora estava cursando Pedagogia.

\section{Execução e análise dos resultados}

A pesquisa foi realizada no dia 29 de setembro de 2018 . Na sua execução, aplicamos uma avaliação aos alunos do $2^{\circ}$ e $3^{\circ}$ ano do ensino médio, da EJA e também a alguns alunos que já haviam concluído o ensino médio, contabilizando um total de 15 alunos cuja identidade foi preservada. A avaliação consistiu em 10 questões objetivas retiradas do Enem dos anos de 2015 e 2016 e de uma questão dissertativa à qual foi corrigida seguindo os critérios do exame nacional. O tema da redação foi a greve dos caminhoneiros que ocorreu no primeiro semestre de 2018. Seguindo a estratégia do Enem para a realização da redação, os alunos puderam contar também com três textos motivadores. A finalidade era avaliar o domínio da modalidade culta da língua; o repertório e tipo textual; o projeto de texto; o uso de elementos de coesão e a proposta de intervenção. Quanto às questões objetivas, estas foram corrigidas de acordo com os gabaritos disponíveis no site do INEP. Avaliamos a prova objetiva em 10 pontos e a prova dissertativa em 1000 pontos. Os resultados individuais foram transcritos na tabela 1 a seguir.

Tabela 1 - Pontuação individual por aluno na prova objetiva e na redação

\begin{tabular}{|l|l|l|l|l|l|l|l|l|}
\hline Aluno & 1 & 2 & 3 & 4 & 5 & 6 & 7 & 8 \\
\hline Escolaridade & $\mathrm{C}$ & $\mathrm{C}$ & $3^{\circ}$. & $3^{\circ}$. & $3^{\circ}$. & $3^{\circ}$. & $3^{\circ}$. & $3^{\circ}$. \\
\hline P. objetiva & 5 & 3 & 4 & 1 & 3 & 1 & 6 & 3 \\
\hline Redação & 360 & 520 & 440 & 320 & 560 & 400 & 400 & 480 \\
\hline
\end{tabular}

\begin{tabular}{|l|l|l|l|l|l|l|l|}
\hline Aluno & 9 & 10 & 11 & 12 & 13 & 14 & 15 \\
\hline Escolaridade & $3^{\mathrm{o}}$. & $3^{\mathrm{o}}$. & $3^{\mathrm{o}}$. & $3^{\mathrm{o}}$. & $2^{\mathrm{o}}$. & $2^{\mathrm{o}}$. & $2^{\mathrm{o}}$. \\
\hline P. objetiva & 7 & 4 & 2 & 1 & 4 & 4 & 3 \\
\hline Redação & 520 & 600 & 440 & 480 & 120 & 240 & 360 \\
\hline
\end{tabular}

Fonte: Elaboração própria

população hoje tem a língua portuguesa como primeira língua, mas iniciaram um movimento de retomada da língua indígena falada por seus ancestrais. 
As médias das notas foram:

Tabela 2 - Média da pontuação dos alunos na prova objetiva e na redação

\begin{tabular}{||l|l||}
\hline Simulado & Média obtida \\
\hline \hline Prova objetiva & 3,4 \\
Redação & 416 \\
\hline \hline
\end{tabular}

Fonte: Elaboração própria

O resultado da prova objetiva revela um baixo nível de proficiência em língua portuguesa. A média de 3,4 evidencia dificuldade dos alunos na interpretação de texto e nossa hipótese é a de que estes alunos não têm o hábito de leitura. Em relação à prova dissertativa, a média 416 indica pouco domínio da língua escrita e nenhum dos alunos alcançou nota satisfatória. Somente um aluno obteve 600 pontos, o que consideramos razoável nesse contexto. As notas obtidas pelos alunos comprovam a baixa proficiência em língua portuguesa e esse pode ser um fator determinante para a pouca inserção destes alunos no nível superior.

As produções escritas dos alunos apresentaram frequentes problemas estruturais, como a não utilização de vírgulas e ponto final, erros de acentuação gráfica, muitas marcas de oralidade (tava, pra), erros de ortografia (uso de mais no lugar de mas), uso inadequado dos porquês, uso do verbo ter no lugar de haver, desvios de concordância, sentenças longas e mal estruturadas e pouco uso de conectivos (operadores argumentativos), sobretudo entre parágrafos. Em relação ao conteúdo, no geral, houve uma argumentação razoável com informações previsíveis, mas faltou maior aprofundamento do tema.

Pôde-se concluir que os alunos não atingiram grau de conhecimento suficiente em língua portuguesa, nem desenvolveram habilidades esperadas para esse nível, aspectos que confirmam a hipótese de que os alunos teriam dificuldades para realizar o Enem tendo em vista as dificuldades demonstradas na interpretação e elaboração de textos, habilidades estas que provêm de uma educação que leva em consideração a importância do letramento na educação básica e o domínio da modalidade de prestígio da língua. Esse resultado, contudo, não surpreende quando comparado ao obtido pelo SAEB ${ }^{11}$ (Sistema de avaliação do ensino básico). No ano de 2017, a média nacional de proficiência em português foi de 267,6 (em uma escala de 0 a 9), resultado classificado como insuficiente pelo MEC. Assim, é possível afirmar, com base na análise das informações, que o ensino ofertado na Escola Estadual Bacumuxa Pataxó é insatisfatório, tal como nas demais escolas das redes públicas do país. Os resultados indicam que há uma ineficácia do ensino médio no Brasil de modo geral. Vale ressaltar que o

${ }^{11}$ Relatório Saeb 2017. Inep Ministério da Educação. Brasil, 2019. Disponível em http://portal.inep.gov.br Acesso em: 26/09/2019 
fato de os falantes terem o português como língua materna pode explicar esse resultado. O desafio é maior quando os falantes são bilíngues ou quando a língua alvo, no caso o português, não é aprendida logo na infância, ou seja, quando é a segunda língua.

Voltando o olhar para a realidade escolar indígena, é oportuno lembrar que houve, nas últimas décadas, incentivos para uma educação intercultural com a aprovação da Lei no. 9394/1996 (Lei de diretrizes da Educação Nacional), que define as matrizes pedagógicas específicas para a formação de professores indígenas. Deste modo, além de se submeterem aos exames regulares para o ingresso nos cursos superiores, passaram a contar também com diversos cursos em várias instituições pelo país, inclusive curso de magistério in ${ }^{12}$ dígena em nível de ensino médio. Esse último, contudo, apenas habilita para a atuação na educação infantil e fundamental, permanecendo uma demanda, em muitas escolas indígenas, de professores para atuar no ensino médio e para enfrentar o grande desafio que é o ensino da língua portuguesa paralelamente ao ensino da língua indígena, além de outros conteúdos. Nesse sentido, voltamos a ressaltar a importância da proficiência em língua portuguesa como meio e fim desse processo.

Diante do insucesso escolar na preparação dos jovens e da persistência de práticas pedagógicas "reducionistas" e "descontextualizadas" das últimas décadas, Antunes (2003) adverte que fatores internos à própria escola condicionam a qualidade dos resultados. Ela admite que causas externas são também responsáveis pelo resultado; a escola reflete as condições gerais da comunidade em que está inserida. Entretanto, segundo a autora, a orientação para o ensino de língua é que se privilegie sua dimensão interacional e discursiva, condição para participação plena do indivíduo na sociedade, diferente de uma atividade de leitura e de escrita mecânica. As práticas muitas vezes são desvinculadas do uso social da linguagem. Espera-se que seja efetivado o processo de letramento, que é tornar o aluno capaz de usar a linguagem em conformidade com as diversas situações comunicativas a que está exposto na vida social.

Sobre esta questão, Magda Soares (2017, p.114) destaca que o espaço escolar é importante para as camadas populares, pois é a instância em que podem ser adquiridos os instrumentos necessários à luta contra a desigual distribuição de privilégios. Uma escola comprometida, segunda a autora, deve direcionar forças progressistas para garantir às camadas populares a aquisição de habilidades que as instrumentalizem a participar do processo de transformação social através de um ensino eficiente. Ressalta que um desses instrumentos é o domínio da variedade linguística de prestígio, mas sem classificar as variedades populares como "deficientes". Ao que parece, em termos gerais, as escolas ainda não estão adotando práticas que resultem em um aprendizado condizente com as expectativas a elas impostas. Do ponto de vista do letramento, leitura e escrita são práticas discursivas inseparáveis de

\footnotetext{
${ }^{12}$ https://download.inep.gov.br/publicacoes/institucionais/avaliacoes e exames da_educacao basica/r elatorio saeb 2017.pdf> p. 94
} 
contextos sociais (KLEIMAN, 2007, p.4). A escola deveria, portanto, ser um espaço para desenvolver essas habilidades.

Reforçamos que as políticas públicas são essenciais para a inclusão - bem como um planejamento curricular que atenda as demandas locais -, preservando e valorizando suas culturas, além de permitir acesso a novos conhecimentos sem que isso acarrete a integração à sociedade não indígena.

\section{Considerações Finais}

Neste artigo, levantamos uma breve discussão sobre o baixo índice de alunos indígenas que cursam ou cursaram ensino superior no Brasil e relacionamos esse resultado ao pouco domínio do português escrito tal como exigido nos exames de seleção para o ingresso nas universidades. Essa constatação foi feita a partir da avaliação do desempenho de alguns alunos do ensino médio e da Eja de uma comunidade Pataxó de Minas Gerais. O resultado mostrou a insuficiência do ensino de língua portuguesa na escola da comunidade, assim como é insuficiente o ensino em outras escolas da rede pública quando comparadas ao resultado do SAEB. Nossa amostra, embora pequena, revela que a escola da comunidade se encontra na média das escolas públicas e, tal como estas, precisa de uma proposta de intervenção para obter resultados mais satisfatórios. Nesse caso, não podemos afirmar que se trata de um problema especificamente localizado na comunidade, apesar da pouca qualificação de boa parte de seus professores. 
Espaço Ameríndio

\section{Referências bibliográficas}

AMARAL, Luiz. Bilinguismo, aquisição, letramento e o ensino de múltiplas línguas em escolas indígenas no Brasil. Cáceres: Cadernos de Educação Escolar Indígena, v.9, n. 1, p.13-32, 2011.

ANTUNES, Irandé. Aula de português: encontro e interação. In. ANTUNES, Irandé. Assumindo a dimensão interacional da linguagem. 8. ed. São Paulo: Parábola editorial, 2003 .

BOMFIM, Anari Braz. Patxohã: a retomada da língua do povo Pataxó. Revista LinguíStica / Revista do Programa de Pós-Graduação em Linguística

da Universidade Federal do Rio de Janeiro. Volume 13, n.1 jan de 2017, p. 303-327. ISSN 2238-975X 1. [https://revistas.ufrj.br/index.php/rl]

BRASIL. Instituto Brasileiro de Geografia e Estatística - IBGE, 2010. Disponível em: $<$ https://indigenas.ibge.gov.br/>. Acesso em: 25 out 2018.

BRASIL. Senado Federal. Constituição da República Federativa do Brasil, de 5 de outubro de 1998, que Regulamenta a Lei $\mathrm{n}^{\circ} 12.711$, de 29 de agosto de 2012, que dispõe sobre o ingresso nas universidades federais e nas instituições federais de ensino técnico de nível médio (1988).

BRASIL. Ministério da Educação. Câmara de Educação Básica. Diretrizes Curriculares Nacionais para a Educação Escolar Indígena. Brasília: MEC/CEB, 2012.

BRASIL. Ministério da Educação. Instituto Nacional de Estudos e Pesquisas Educacionais Anísio Teixeira. Exame Nacional do Ensino Médio, 1998.

BRASIL. Ministério da Educação. Estatísticas Sobre Educação Escolar Indígena no Brasil. Instituto Nacional de Estudos e Pesquisas Educacionais Anísio Teixeira. Brasília, 2007.

BRASIL. Ministério da Educação. Programa Bolsa Permanência, 2013. Disponível em: http://permanencia.mec.gov.br. Acesso em 27 abr. 2018.

BRASIL. Ministério da Educação. Prolind, 2008. Disponível em: http://portal.mec.gov.br/prolind . Acesso em 27 abr. 2018.

CAMPETELA, Cilene. Proposta de material didático para ensino e aprendizagem do Português como segunda língua em escolas indígenas. Macapá: Letras Escreve, v. 4, n. $1,2014$.

FERNANDES, Cleide Pereira. Letramento em língua portuguesa: um instrumento para o ingresso indígena na universidade. Trabalho de Conclusão de Curso Faculdade de Ciências Sociais Aplicadas de Belo Horizonte - FACISABH, Belo Horizonte, 2019. 
Espaço Ameríndio

KLEIMAN, Ângela. Letramento e suas implicações para o ensino de língua materna. Santa Cruz do Sul: Signo, v.32, n.53, p.1-25, dez, 2007.

MAIA, Marcus; FRANCHETTO, Bruna; STORTO, Luciana; e SANDALO, Filomena. A construção do conhecimento linguístico: do saber do falante à pesquisa. Cuiabá: Cadernos de Educação Escolar Indígena, v.1, p.47-78, 2002.

SOARES, Magda. Linguagem e Escola: uma perspectiva social. 18 ed. São Paulo: Contexto, 2017.

Recebido em: 17/10/2020 * Aprovado em: 21/03/2021 * Publicado em: 28/04/2021 